\title{
Efeitos de probióticos sobre a digestibilidade, escore fecal e características hematológicas em cães
}

[Effects of probiotics on digestibility, faecal score, and hematologic characteristics in dogs]

\author{
M.A.R. Feliciano ${ }^{1}$, F.M.O.B. Saad $^{2}$, P.V.R. Logato $^{2}$, A.A. Aquino ${ }^{3}$, V.A. José $e^{3}$, N.C. Roque ${ }^{3}$ \\ ${ }^{1}$ Aluno de pós-graduação - FCAV-UNESP - Jaboticabal, SP \\ ${ }^{2}$ Departamento de Zootecnia - UFLA - Lavras, MG \\ ${ }^{3}$ Aluna de pós-graduação - UFLA - Lavras, MG
}

\begin{abstract}
RESUMO
Avaliaram-se os efeitos da suplementação de dois tipos de probióticos para cães filhotes, que receberam dois tipos de dieta - de alta e de baixa qualidade -, sobre a digestibilidade dos nutrientes, escore fecal e parâmetros sanguíneos. Foram utilizados 18 animais, distribuídos em três tratamentos. No tratamento 1 , controle, os cães receberam somente a ração; no tratamento 2, ração com probiótico 1 (Bifidobacterium) e, no tratamento 3, ração com probiótico 2 (Lactobacillus). O experimento foi dividido em duas fases. Verificaram-se que os valores médios do coeficiente de metabolizabilidade da energia bruta (CMEB) na fase 1, caracterizada pela troca da dieta Super Premium para a dieta Standard, apresentaram resultados significativos $(\mathrm{P}<0,05)$, sendo os melhores resultados obtidos nos animais que receberam o probiótico 2 . Não houve diferenças significativas $(\mathrm{P}>0,05)$ para o escore fecal e para as análises hematológicas.
\end{abstract}

Palavras-chave: cão, probiótico, digestibilidade

\begin{abstract}
The effects of supplementation of two probiotics to puppies fed two diets - high and low quality - on nutrient digestibility, faecal score, and blood parameters were evaluated using 18 animals in three treatments. In the treatment 1, control, the dogs received only food; in the treatment 2, food with probiotic 1 (Bifidobacterium) and in the treatment 3, food with probiotic 2 (Lactobacillus). The research was divided in two phases. It was verified that crude metabolizability energy coefficient average values in the phase 1, characterized to changing Super Premium food to Standard, presented significant results $(P<0.05)$ and the best ones were obtained in animals that received the probiotic 2. No differences $(P>0.05)$ on faecal score and blood analysis were obtained.
\end{abstract}

Keywords: dog, probiotic, digestibility

\section{INTRODUÇÃO}

Os probióticos são definidos como aditivos alimentares, que contêm microrganismos vivos que afetam positivamente $\mathrm{e}$ beneficiam $\mathrm{o}$ hospedeiro e que equilibram a microbiota intestinal (Tomasik e Tomasik, 2003). São mais comum e eficientemente utilizados em ocasiões estressantes, como na desmama, na mudança de alimentação, na falha na ingestão do colostro, no transporte, em alta concentração de animais, nas doenças concorrentes e após tratamento com antibióticos (Fernandez et al., 2000). Os probióticos são considerados ferramentas alternativas no tratamento e na prevenção das diarreias, pois contêm microrganismos benéficos que ajudam a suprimir os patogênicos (Batista et al., 2008).

Em cães, Swanson et al. (2002) verificaram que a administração de Lactobacillus acidophilus aumentou a digestibilidade da matéria seca, da matéria orgânica e da proteína bruta. Segundo Rutz e Lima (2001), ainda há poucas evidências

Recebido em 12 de janeiro de 2009

Aceito em 16 de novembro de 2009

E-mail: marcusfeliciano@yahoo.com.br 
para afirmar que os probióticos influem positivamente na digestibilidade de nutrientes, o que é confirmado pela ausência de resultados benéficos em alguns trabalhos.

Pasupaty et al. (2001), ao avaliarem a suplementação de probióticos para filhotes de cães com 10 semanas de idade, sem raça definida, não encontraram diferenças significativas na digestibilidade da matéria seca, da matéria orgânica, da proteína e da energia bruta. O mesmo foi citado por Biourge et al. (1998) em relação à matéria seca, à proteína, ao lipídeo e à energia metabolizável. Resultados negativos no uso de probióticos para cães foram encontrados por Hesta et al. (2003), que verificaram que a adição desses suplementos à dieta pode diminuir a digestibilidade aparente da proteína, desconhecendo-se, no entanto, o mecanismo pelo qual isso ocorre.

O escore fecal é utilizado para avaliar as características das fezes, como consistência, forma e umidade. Estas estão associadas à digestibilidade do alimento e para essa avaliação utiliza-se uma escala que varia de 1 a 5 (Flickinger et al., 2003; Veronesi, 2003). Normalmente, os probióticos favorecem a digestão dos alimentos, melhorando as características das fezes, ou seja, mantêm um escore fecal proporcional à digestibilidade (Veronesi, 2003).

De acordo com Marcinakova et al. (2006), as proteínas séricas apresentam-se diminuídas devido à administração de probióticos. Assim, a análise das proteínas plasmáticas pode ser empregada como método de avaliação do estado nutricional do animal. A concentração sérica de albumina pode ser indicador do conteúdo de proteína na dieta, muito embora as mudanças ocorram lentamente (Thomas, 2000).

Melo et al. (2006) descreveram que a porcentagem de proteína na dieta altera algumas variáveis hematológicas, como proteínas e eritrograma, sem prejudicar o sistema de defesa orgânico. Dessa forma, sabe-se que a dieta tem papel importante na produção de proteínas e suas frações, mas não se sabe a relação entre essa síntese de proteínas e a suplementação de probióticos, pois ainda não foi descrita na literatura a associação entre o uso destes suplementos com a produção de proteínas totais séricas e suas frações em cães.

O objetivo deste trabalho foi avaliar os efeitos da suplementação de dois tipos de probióticos para cães filhotes da raça Beagle, que receberam dois tipos de dieta - de alta e de baixa qualidade -, sobre a digestibilidade dos nutrientes, o escore fecal e os parâmetros sanguíneos.

\section{MATERIAL E MÉTODOS}

O delineamento experimental utilizado no experimento foi o inteiramente ao acaso, com três tratamentos e seis repetições, totalizando 18 unidades experimentais, para todos os parâmetros avaliados. $\mathrm{O}$ experimento foi realizado no Núcleo de Estudos em Nutrição de Animais de Companhia, Departamento de Zootecnia da Universidade Federal de Lavras. Foram utilizados 18 cães da raça Beagle, filhotes de dois a seis meses de idade, machos e fêmeas, com pesos entre 5 e $7 \mathrm{~kg}$, distribuídos ao acaso em três tratamentos. Tratamento 1 - controle, foi administração somente ração, no tratamento 2 ração mais probiótico 1 e no tratamento 3 ração mais probiótico 2 .

A ração foi fornecida aos animais de forma controlada, duas vezes ao dia, pela manhã e no final da tarde. O probiótico 1 continha em sua formulação Bifidobacterium 1,0 x $10^{8} \mathrm{UFC} / \mathrm{g}$, Lactobacillus 9,1 x $10^{7} \mathrm{UFC} / \mathrm{g}$ e Enterococcus $1,2 \times 10^{8} \mathrm{UFC} / \mathrm{g}$. O probiótico 2, Lactobacillus $4,3 \times 10^{8} \mathrm{UFC} / \mathrm{g}$, Enterococcus $3,1 \times 10^{8} \mathrm{UFC} / \mathrm{g}$ e Pediococcus $3,5 \times 10^{8} \mathrm{UFC} / \mathrm{g}$.

O experimento foi dividido em duas fases. A fase 1 caracterizou-se pela avaliação e comparação dos efeitos dos probióticos com a mudança de uma dieta de alta qualidade (Super Premium) para uma dieta comercial padrão (Standard); na fase 2, pela avaliação e comparação dos efeitos dos probióticos com a mudança de uma dieta comercial Standard para uma dieta Super Premium.

$\mathrm{Na}$ primeira fase, os animais passaram por adaptação nutricional de 11 dias com ração Super Premium. No $12^{\circ}$ dia, foi realizado jejum de 24 horas. No $13^{\circ}$ dia, os animais passaram a receber ração Standard e iniciou-se a suplementação com probióticos via oral (com exceção do tratamento-controle), a cada 12 
horas, na posologia recomendada pelo fabricante (três gramas diários para cada cão, recomendado para animais em estresse ou doença inflamatória do trato gastrintestinal). Após 11 dias de adaptação e anteriormente ao jejum de 24 horas e troca da ração, foi realizada a coleta de sangue para mensuração de proteínas totais séricas e frações.

A mensuração de escore fecal foi iniciada após o jejum (início da administração de probióticos) e estendeu-se por oito dias (início da fase 2). A coleta de fezes para digestibilidade iniciou-se após o final da administração do probiótico (15 dias após cada adaptação) e estendeu-se por cinco dias consecutivos. No último dia de administração dos probióticos, foi repetida a coleta de sangue para cada tratamento.

$\mathrm{Na}$ segunda fase, os animais passaram por adaptação nutricional de sete dias com ração comercial Standard e procedeu-se à troca da ração para a Super Premium, antes da suplementação com os probióticos. Igualmente à fase 1 , no dia anterior à troca, os animais foram submetidos a jejum de 24 horas. Os demais procedimentos foram semelhantes aos da fase 1 .

As fezes eram colhidas antes do fornecimento da alimentação aos animais. Após o período de coleta, as amostras de fezes foram descongeladas e processadas para determinação da matéria seca, proteína bruta e energia bruta.

A determinação do escore fecal foi feita por meio de observação visual das fezes e suas características e graduação em uma escala de 1 a 5: escore 1 - fezes muito duras e ressecadas com pellets secos e pequenos; escore 2 - fezes duras, secas, firmes, macias e bem formadas; escore 3 fezes macias, bem formadas, úmidas, com formato preservado; escore 4 - fezes macias, sem forma definida; escore 5 - fezes líquidas, segundo o proposto por Veronesi (2003).

As amostras de sangue foram acondicionadas em frascos Vacutainer $^{B}$ e analisadas quanto às concentrações de proteínas totais e fracionadas, pelo método de análise colorimétrica.

Os dados foram previamente testados para normalidade dos resíduos e homogeneidade das variâncias (teste F). Quando essas premissas não eram respeitadas, era realizada a transformação logarítmica. As médias reais ou transformadas foram avaliadas por meio de análise de variância e a comparação de médias pelos testes Tukey e $t$, no PROC MEANS-SAS ${ }^{\mathbb{R}}$, SAS/1985, sendo utilizados o desvio-padrão da média e o coeficiente de variância como dados para comparação dos resultados e sua viabilidade. As variáveis qualitativas, como o escore fecal, foram avaliadas pelo teste Kruskal-Wallis.

\section{RESULTADOS E DISCUSSÃO}

A suplementação com probióticos não alterou $(\mathrm{P}>0,05)$ os coeficientes de digestibilidade da matéria seca e da proteína bruta, na fase 1. Estes dados diferem dos de Hesta et al. (2003), que observaram diminuição desses parâmetros, e dos dados de Swanson et al. (2002), que observaram que a administração de Lactobacillus acidophilus aumentava a digestibilidade da matéria seca e da proteína bruta.

A troca da ração de Standard para Super Premium (fase 2) também não contribuiu com diferenças significativas $(\mathrm{P}>0,05)$ nos dados de matéria seca e proteína, mas isso não pode ser comparado com o uso de probiótico e sim com a melhoria da alimentação (qualidade de ingredientes).

Os valores médios do coeficiente de metabolizabilidade da energia bruta (CMEB) na fase 1, caracterizada pela troca de dieta Super Premium para a Standard, apresentaram resultados significativos (Tab. 1), ou seja, a utilização do probiótico 2 obteve melhores resultados que os outros tratamentos, sugerindose que a utilização deste seja mais efetiva para a digestibilidade. Isso indica que entre as bactérias benéficas os Lactobacillus foram os microrganismos mais efetivos na digestibilidade de nutrientes, neste experimento.

Como não foram encontradas diferenças significativas para os coeficientes de digestibilidade da energia bruta, os resultados sugerem que os Lactobacillus podem ter auxiliado na diminuição da excreção de nitrogênio pela urina, aumentando, assim, o coeficiente de metabolizabilidade da energia bruta. Isso foi anteriormente proposto por Korniewicz (1992), citado por Correa et al. (2002), ao encontrar resultados semelhantes com o uso de probióticos em leitões. 
Tabela 1. Valores médios de coeficiente de digestibilidade da energia bruta (CDEB) e coeficiente de metabolizabilidade da energia bruta (CMEB), caracterizados pela troca de uma dieta Super Premium para uma dieta comercial Standard, para filhotes de cães Beagle, segundo o tipo de tratamento, na fase 1

\begin{tabular}{ccc}
\hline Tratamento & \multicolumn{2}{c}{ Média } \\
\cline { 2 - 3 } & CDEB & CMEB \\
\hline Controle & $82,06 \pm 2,45$ & $77,21 \pm 2,09 \mathrm{~B}$ \\
Probiótico 1 & $84,72 \pm 3,98$ & $77,64 \pm 3,45 \mathrm{~B}$ \\
Probiótico 2 & $82,06 \pm 1,40$ & $80,73 \pm 1,30 \mathrm{~A}$ \\
\hline CV (\%) & 3,40 & 3,18 \\
\hline
\end{tabular}

Médias seguidas de letras distintas, na coluna, diferem pelo teste Tukey em nível nominal de significância de 5\%. Probiótico 1: Bifidobacterium; Probiótico 2: Lactobacillus

Fase 1: avaliação e comparação dos efeitos dos probióticos com a mudança de uma dieta de alta qualidade (Super Premium) para uma dieta comercial padrão (Standard).

Esse efeito foi observado na fase de troca de uma ração de maior para uma de menor qualidade de ingredientes, tendo um efeito quando o valor biológico da proteína é diminuído e a utilização de proteína como fonte energética e geração de catabólitos é maior. A melhora no coeficiente de metabolizabilidade, com a ausência de resultados no coeficiente de digestibilidade de energia, reforça o papel dos probióticos na conservação do nitrogênio, pois cerca de $40 \%$ desse elemento é excretado na urina (Marcato e Lima, 2005).

Essa melhor utilização do nitrogênio poderia ser resultado da hidrólise bacteriana, com aumento da biodisponibilidade de aminoácidos livres (Saad, 2006) ou, então, pela produção de ácido butírico, que serve como fonte de energia para colonócitos (cerca de $70 \%$ do consumo energético dessas células), economizando o uso de aminoácidos pelas células intestinais (Scheppach, 1994).

Ao contrário do ocorrido na fase 1 , não foram observadas diferenças $(\mathrm{P}>0,05)$ na fase 2 , com a substituição de ração Standard para Super Premium. Possivelmente, esses resultados foram devidos à alta qualidade e ao melhor perfil aminoacídico da ração Super Premium. Esse melhor perfil de aminoácidos, possivelmente, incrementou o valor biológico da proteína dietética, diminuindo a excreção de nitrogênio urinário.

Os dados deste experimento diferem dos dados obtidos por Biourge et al. (1998) que, ao utilizarem Lactobacillus para cães, não obtiveram resultados positivos sobre o coeficiente de metabolizabilidade da energia.

Para determinar se a melhora na utilização do nitrogênio, que possivelmente resultou em maior coeficiente de metabolizabilidade da energia, é uma ação direta da bactéria ou de melhor aproveitamento no intestino delgado, poderiam ser realizadas avaliações da digestibilidade ileal. No entanto, tal procedimento além de ser contra os princípios dos comitês de ética e bem-estar animal quanto à experimentação com animais de companhia, também apresenta complicações comuns à espécie, como infecção da ferida cirúrgica, rotação da cânula, peritonite e enterite, o que limitaria sua realização (Vasconcellos, 2005).

Os resultados demonstram que o efeito do probiótico não foi significativo $(\mathrm{P}>0,05)$ para energia metabolizável, ou seja, houve semelhança na digestibilidade, independentemente de seu uso ou de seu tipo, o que difere das citações de Hesta et al. (2003), Nutrient ... (2006) e Marcinakova et al. (2006). Esses autores comentaram que poderia haver diminuição da digestibilidade e da disponibilização de nutrientes com o uso de probióticos, devido à produção excessiva de metabólitos por parte das bactérias, que poderiam ter ação irritativa sobre a mucosa do cólon. No entanto, em concentrações moderadas, poderiam trazer efeitos benéficos (Soares, 1996, citado por Correa et al., 2002).

Swanson et al. (2002) citaram que Lactobacillus e Bifidobacterium são produtores de lactato e butirato. Esses metabólitos podem ser convertidos em energia, na cadeia metabólica, corroborando, dessa forma, com os dados expostos nas tabelas deste estudo.

Os escores fecais são apresentados nas Tab. 2 e 3. 
Tabela 2. Valores do escore fecal verificados na fase 1 do experimento, caracterizada pela troca de uma dieta Super Premium para uma dieta comercial Standard, para filhotes de cães Beagle

\begin{tabular}{cccc}
\hline \multirow{2}{*}{ Escore } & \multicolumn{3}{c}{ Fase 1 } \\
\cline { 2 - 4 } & Controle & Probiótico 1 & Probiótico 2 \\
\hline 1 & 0 & 0 & 0 \\
2 & 2 & 2 & 0 \\
3 & 38 & 40 & 42 \\
4 & 1 & 0 & 0 \\
5 & 1 & 0 & 0 \\
\hline Total & 42 & 42 & 42 \\
\hline
\end{tabular}

Teste estatístico de Kruskal-Wallis em nível nominal de significância de 5\%.

Probiótico 1: Bifidobacterium; Probiótico 2: Lactobacillus

Escore das fezes de acordo com Veronesi (2003).

Fase 1: avaliação e comparação dos efeitos dos probióticos com a mudança de uma dieta de alta qualidade (Super Premium) para uma dieta comercial padrão (Standard).

Tabela 3. Valores do escore fecal verificados na fase 2 do experimento, caracterizada pela troca de uma dieta comercial Standard para uma dieta Super Premium, para filhotes de cães Beagle

\begin{tabular}{cccc}
\hline \multirow{2}{*}{ Escore } & \multicolumn{3}{c}{ Fase 2 } \\
\cline { 2 - 4 } & Controle & Probiótico 1 & Probiótico 2 \\
\hline 1 & 0 & 0 & 0 \\
2 & 25 & 25 & 23 \\
3 & 12 & 8 & 10 \\
4 & 1 & 7 & 9 \\
5 & 4 & 2 & 0 \\
\hline Total & 42 & 42 & 42 \\
\hline
\end{tabular}

Teste estatístico de Kruskal-Wallis em nível nominal de significância de 5\%.

Probiótico 1: Bifidobacterium; Probiótico 2: Lactobacillus

Escore das fezes de acordo com Veronesi (2003).

Fase 2: avaliação e comparação dos efeitos dos probióticos com a mudança de uma dieta comercial padrão (Standard) para uma dieta de alta qualidade (Super Premium).

$\mathrm{Na}$ fase 2, grande parte dos escores fecais encontraram-se distribuídos na classificação 2 (Fig. 1), diferente do encontrado na fase 1 , em que a maioria concentrava-se no escore 3. Podese conjecturar que o aumento da qualidade do alimento foi o responsável por incrementar o escore fecal obtido nesta fase.

Não houve diferenças significativas para o escore fecal, o que não corrobora com Veronesi (2003), que relata que os probióticos melhoram a digestibilidade dos nutrientes, mantendo um escore fecal condizente com este nível de digestibilidade. No entanto, concordam com Swanson et al. (2002), que observaram as mesmas características de escore fecal com a utilização de probióticos.

No presente estudo, a não observação de efeito na digestibilidade dos nutrientes refletiu no escore fecal. De qualquer forma, é importante ressaltar que os escores na fase 2 , na troca do alimento de menor para o de melhor qualidade e em que a digestibilidade de nutrientes e energia foram maiores, foram melhores do que os apresentados na fase 1. Isso nos sugere que a utilização de probióticos pode apresentar um efeito benéfico quando se trabalha com dietaspadrão.

Por meio dos dados obtidos, foi possível verificar aumentos médios nos níveis sanguíneos de albuminas e proteínas totais na fase 2 do experimento, em relação à data, provavelmente, em detrimento da ração oferecida aos animais (Super Premium). A ração oferecida na fase 2 tinha $6 \%$ de proteína a mais que a ração Standard, na matéria seca, apresentando melhor qualidade do produto, sugerindo apenas melhora dos níveis com a utilização da dieta. 


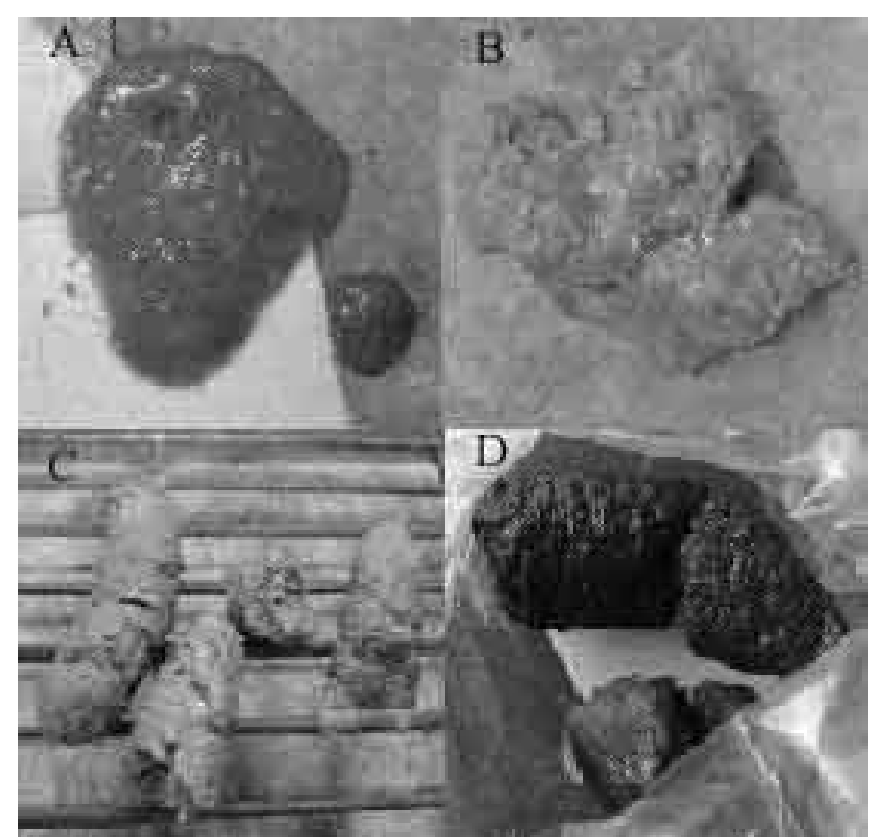

Figura 1. Escores das fezes de filhotes de cães Beagle: A) escore fecal 5; B) escore fecal 4; C) escore fecal 3 e D) escore fecal 2.

\section{CONCLUSÃO}

Os probióticos não foram similares em sua eficácia. O melhor probiótico é aquele contendo Bifidobacterium e maior concentração de Lactobacillus (probiótico 2). Recomenda-se o probiótico 2 como melhor probiótico, pois apresentou efeitos positivos no trato gastrintestinal, principalmente quando administrado juntamente com dietas de menor qualidade de ingredientes.

\section{REFERÊNCIAS BIBLIOGRÁFICAS}

BATISTA, C.G.; COELHO, S.G.; RABELO, E. et al. Desempenho e saúde de bezerras alimentadas com leite sem resíduo de drogas antimicrobianas ou leite de vacas tratadas contra mastite adicionado ou não de probiótico. Arq. Bras. Med. Vet. Zootec., v.60, p.185191, 2008.

BIOURGE, V.; VALLET, C.; LEVESQUE, A. et al. The use of probiotics in the diet of dogs. J. Nutr., v.128, p.2730-2732, 1998.

CORREA, G.S.S.; GOMES, A.V.C.; CORREA, A.B. Digestibilidade da ração de frangos de corte suplementados com probióticos e antibiótico. Cienc. Rural, v.32, p.687-691, 2002.
FERNANDEZ, P.C.C.; LADEIRA, I.Q.; FERREIRA, C.L.L.F. et al. Viabilidade do uso de probióticos na alimenação de monogástricos. Cad. Tec. Vet. Zootec., n.31, p.53-71, 2000.

FLICKINGER, E.A.; SCHREIJEN, E.M.W.C.; PATIL, A.R. et al. Nutrient digestibilities, microbial populations, and protein catabolites as affected by frutan supplementation of dog diets. J. Anim. Sci., v.81, p.2008-2018, 2003.

HESTA, M.; ROOSEN, W.; JANSSENS, G.P.J. et al. Probiotics affect nutrient digestibility but not faecal ammonia in dogs fed increased dietary protein levels. Br. J. Nutr., v.90, p.1007-1014, 2003.

MARCATO, S.M.; LIMA, G.J.M.M. Efeito da restrição alimentar como redutor do poder poluente dos dejetos de suínos. Rev. Bras. Zootec., v.34, p.855$863,2005$.

MARCINAKOVA, M.; SIMONOVA, M.; STROMPFOVA, V. et al. Oral applications of Enterococcus faecium strain EE3 in healthy dogs. Fol. Microbiol., v.51, p.239-242, 2006.

MELO, J.F.B.; DIAS, M.T.; LUNDESTEDT, L.M. et al. Efeito do conteúdo de proteína na dieta sobre os parâmetros hematológicos e metabólicos do bagre sulamericano Rhamdia quelen. Rev. Cienc. Agron., v.1, p.43-51, 2006. 
NUTRIENT requirements of dogs and cats. Washington: National Academy Press, 2006. p.347.

PASUPATHY, K.; SAHOO, A.; PATHAK, N.N. et al. Effect of lactobacillus supplementation on growth and nutrient utilization in mongrel pups. Arch. Tierernahr., v.55, p.243-253, 2001.

RUTZ, F.; LIMA, G.J.M.M. O uso de antimicrobianos como promotores de crescimento no Brasil. In: CONGRESSO BRASILEIRO DE VETERINÁRIOS ESPECIALISTAS EM SUÍNOS, 10, 2001, Porto Alegre, RS. Anais... Concórdia, SC: CNPSA, 2001. 10p. CD-ROM.

SAAD, S.M.I. Probióticos e prebióticos: o estado da arte. Rev. Bras. Cienc. Farm., v.42, p.1-16, 2006.

SCHEPPACH, S. Effects of short chain fatty acids on gut morphology and function. Gut, v.35, suppl., p.S35S38, 1994.

SWANSON, K.S.; GRIESHOP, C.M.; FLICKINGER, E.A. et al. Fructooligosaccharides and Lactobacillus acidophilus modify bowel function and protein catabolites excreted by healthy humans. J. Nutr., v.132, p.3042-3050, 2002.
THOMAS, J.S. Overview of plasma protein. In: FELDMAN, B.F.; ZINKL, J.G.; JAIN, N.C. (Ed.). Schalm's veterinary hematology. 5.ed. Philadelphia: Lippincott Williams \& Wilkins, 2000. p.891-898.

TOMASIK, P.J.; TOMASIK, P. Probiotics and prebiotics. Cereal Chem., v.80, p.113-117, 2003.

VASCONCELLOS, R.S. Métodos in vivo para avaliação de alimentos industrializados para cães e gatos. In: SIMPÓSIO SOBRE NUTRIÇÃO DE ANIMAIS DE ESTIMAÇÃO, 5., 2005, Campinas, SP. Anais... Campinas: CBNA, 2005. p.133-144.

VERONESI, C. Efeito de dois alimentos comerciais secos no consumo energético, peso vivo e peso metabólico, escore corporal, escore e peso fecal de cães adultos em manutenção e atividade. 2003. 93f. Dissertação (Mestrado) - Universidade de São Paulo, São Paulo. 